\title{
Sistemas de Valores e Atitudes Democráticas de Estudantes Universitários de João Pessoa
}

\author{
Cicero Pereira ${ }^{1}$ \\ Universidade Católica de Goiás \\ Marcus Eugênio Lima \\ Universidade de Lisboa, Portugal \\ Leoncio Camino \\ Universidade Federal da Paraíba
}

\begin{abstract}
Resumo
Este artigo apresenta duas pesquisas empíricas que analisam a relação entre sistemas de valores e atitudes democráticas de estudantes universitários. No primeiro estudo $(n=350)$, investigam-se as dimensões subjacentes à estrutura e ao conteúdo do sistema de valores de estudantes de uma universidade pública. Na interpretação das dimensões obtidas considera-se a teoria de Schwartz sobre os tipos motivacionais e a teoria de Inglehart sobre os valores materialistas e pós-materialistas. Os resultados mostram que os valores se organizam em função de três sistemas: o religioso; o materialista; o pós-materialista. No segundo estudo $(n=200)$, repetem-se os resultados do Estudo 1 numa amostra de estudantes de uma universidade privada, e relacionase a estrutura de valores obtida com as atitudes democráticas. Constata-se que a adesão ao sistema de valores religiosos associase com a atitude negativa em relação à democracia, enquanto que esta atitude se relaciona positivamente com os valores pósmaterialistas. A discussão girou em torno do significado da democracia para estes estudantes.

Palavras-chave: Sistema de valores; atitude; democracia.
\end{abstract}

\begin{abstract}
This paper presents two empirical studies analysing the relationships between individual's value systems and democratic attitudes. The subjects were university students in João Pessoa (Brazil). In the first study $(n=350)$ we investigated the implicit dimensions present in both content and structure of student's value systems. The data were analysed from the framework of Schwartz's Theory of Values and Inglehart's distinction between materialist and post-materialist values. In the second study $(n=200)$ those results were replicated and were also correlated to student's democratic attitudes. The main results were twofold. First, religious values were negatively correlated to democratic attitudes and second the post-materialist values were positively correlated to those attitudes. These findings were discussed pointing out the real meaning of democracy for those subjects.

Keywords: Value systems; attitudes; democracy.
\end{abstract}

Value Systems and Democratic Attitudes in University Students of João Pessoa

Os valores ocupam um espaço fundamental nos sistemas políticos (Bem, 1973; Cochrane, Billig \& Hogg, 1979; Rokeach, 1979a), que devem ser entendidos como arenas onde se travam as lutas pelo poder e que são constituídos tanto pelas estruturas jurídico-políticas, que legalizam os meios de obtenção do poder, quanto pelas diversas concepções políticas que se contrapõem no interior da sociedade (Bobbio, 1993a; Bottomore, 1979). Deve-se considerar, por um lado, que o exercício do poder só é possível através da prática dos valores que sustentam as estruturas jurídico-políticas dos regimes (Bobbio, 1994; Camino, Lima \& Torres, 1997; Dallari, 1989; Lipset, 1967). Por outro lado, as doutrinas políticas,

\footnotetext{
${ }^{1}$ Endereço para Correspondência: Grupo de Pesquisa em Comportamento Político, Cx. Postal 5069, Cidade Universitária, 58051-970, João Pessoa, Paraíba. E-mail: cicerorpereira@yahoo.fr
}

mesmo as apresentadas como propostas científicas, constituem-se mais em discursos sobre valores do que sobre fatos (Levi, 1993).

O papel político dos valores é tão fundamental que se pode afirmar que os sistemas políticos se desenvolvem a partir da hierarquização dos valores numa sociedade (Easton, 1965) e sua interpretação é possível através dos valores coletivos que os sustentam (Dawson, 1979; Seliktar, 1991). As tentativas teóricas de análise da política, desde Aristóteles até os dias atuais, procuram localizar um valor ou um conjunto de valores que seja universal nas relações sociais (Heller, 1991; Parsons, Shils \& Olds, 1968). Com base nessas idéias, este artigo analisa a estrutura e o conteúdo do sistema de valores de estudantes universitários da cidade de João Pessoa, assim como a relação existente entre adesão a esses sistemas e a atitude democrática dos estudantes. 


\section{Valores: Natureza e Influência na Política}

Rokeach (1973) define o valor como uma "crença duradoura de que um modo específico de conduta ou estado final de existência é pessoal ou socialmente preferível a um modo de conduta ou estado final de existência oposto ou inverso. Um sistema de valor é uma organização duradoura de crenças em relação a modos de conduta preferíveis ou estados finais de existência ao longo de um contínuo de importância relativa” (p. 3). Os valores, portanto, servem como padrões ou critérios que orientam as ações, escolhas, julgamentos, atitudes e explicações sociais (Rokeach, 1979b; Williams, 1979), estão entre as crenças avaliativas mais importantes (Feather, 1990; Seligman \& Katz, 1996) e ocupam uma posição central na rede cognitiva que fundamenta as atitudes (Rokeach, 1968). Além disso, são amplamente compartilhados pelos grupos sociais e sua validade é raramente questionada (Maio \& Olson, 1998).

Utilizando um conjunto de 24 valores, Rokeach (1968) analisou textos das principais ideologias políticas comunismo, fascismo, capitalismo e socialismo -, verificando que os escritos políticos se diferenciavam na freqüência do uso dos valores liberdade e igualdade. $\mathrm{O}$ texto sobre capitalismo colocava a liberdade no primeiro lugar e a igualdade entre os últimos. O texto comunista mostrou um resultado oposto: a igualdade em primeiro lugar e a liberdade no último. Os textos socialistas (são textos que defendem uma posição liberal nos termos da política norte-americana e que apresentam uma visão humanista da sociedade) colocavam a liberdade e a igualdade nos dois primeiros lugares, enquanto que um texto do Main Kampt Nazista de Hitler situava-os como os menos importantes. Estes resultados levaram-no a supor que o posicionamento político dos indivíduos poderia traduzir o conflito ideológico expresso nos valores liberdade e igualdade.

Com uma escala composta por 18 valores instrumentais e 18 terminais, Rokeach (1973) analisou a influência deles sobre as atitudes dos americanos diante das manifestações pelos direitos civis. Observou que os indivíduos que simpatizavam e participavam das manifestações por estes direitos ordenaram a liberdade em primeiro e a igualdade em terceiro lugar. Já para as pessoas que simpatizavam mas não participaram destes movimentos, a liberdade ocupava o primeiro e a igualdade o sexto lugar. Finalmente, os que não simpatizavam e não participavam das manifestações, colocaram a liberdade em segundo lugar e a igualdade no último. Com base nestes resultados, o autor concluiu que os valores liberdade e igualdade constituíam dimensões fundamentais das ideologias políticas, demarcando espaços diferencia- dos na arena política ao estabelecer o conflito fundamental entre esses dois valores: a liberdade (compreendida numa perspectiva individualista), e a igualdade (entendida numa abordagem coletivista) (Kinder \& Sears, 1985).

Considerando que o contexto político britânico era mais adequado para analisar a relação entre esses dois valores e o posicionamento ideológico dos indivíduos, Cochrane e colaboradores (1979) realizaram um estudo e constataram que, de fato, os simpatizantes dos partidos comunista e socialista colocavam a igualdade nos primeiros postos da sua hierarquia de valores (segundo e terceiro, respectivamente), enquanto os dos partidos fascista e conservador situavam-na nos últimos lugares (décimo segundo e décimo oitavo, respectivamente). A valorização da liberdade não se diferenciou em função da identificação partidária dos britânicos. Contudo, o modelo foi mais eficiente na descrição de outras dimensões da arena política. Assim, os que preferiam os partidos de esquerda situavam a igualdade e a liberdade nos primeiros postos de sua hierarquia de valores, ao passo que os de direita colocavam a liberdade em terceiro lugar e a igualdade em décimo quarto. Numa pesquisa desenvolvida na Austrália, Feather (1985) verificou que o voto em partidos conservadores correlacionava-se negativamente com a valorização da igualdade. Em outros estudos, o mesmo autor (Feather, 1979, 1984, 1989) observou que eleitores de extrema-direita enfatizavam os valores autoridade, conformidade e tradição, dando pouca ênfase a valores comunitários e igualitários. Finalmente, Feather (1993) verificou que os universitários da Austrália que votavam em partidos liberais de direita eram mais autoritários que os que votavam na esquerda trabalhista.

Em síntese, esses estudos mostram que a adesão aos valores liberdade e igualdade influencia o posicionamento político dos indivíduos; entretanto, essa adesão deve ser contextualizada econômica e culturalmente. Middendorp (1978), por exemplo, mostrou que a esquerda valoriza mais a liberdade de expressão e a igualdade econômica, enquanto a direita prioriza a livre iniciativa econômica e a obediência de todos à autoridade. Mais radicalmente ainda, Lima (1997) constatou que a liberdade e a igualdade não se opõem, mas compõem um sistema de valores vinculados ao bem-estar social. Segundo Vala (1993), as pesquisas empíricas, ao forçar a escolha por um desses valores, criam um artefato metodológico-ideológico e naturalizam uma oposição que pode não ocorrer no contexto sócio-político atual. Além disso, na abordagem de Rokeach (1973) estuda-se a relação entre um ou dois valores e uma atitude ou comportamento político sem ter em conta que os valores constituem-se em padrões 
ou sistemas de valores. Segundo Tamayo, Pimenta, Rolim, Rodovalho e Castro (1996), o posicionamento político dos indivíduos não é guiado pela adesão atribuída a um valor isoladamente, mas por um conjunto de valores que influenciam simultaneamente esse posicionamento.

Apesar dessas criticas, os estudos de Rokeach (1968, 1973) influenciaram as várias teorias sobre valores (Bond, 1988; Braithwaite \& Law, 1985; Chinese Culture Connection, 1987). Na psicologia, por exemplo, a teoria dos tipos motivacionais define o valor como "uma concepção individual de uma meta (terminal ou instrumental) transituacional que expressa interesses (individualistas, coletivistas ou ambos) concernente a um domínio motivacional e avaliado sobre uma classificação de importância como um princípio guia na vida das pessoas" (Schwartz \& Bilsky, 1987, p. 553). Schwartz (1992) apresentou dez tipos de valores que seriam universais nas relações sociais: poder, realização, hedonismo, estimulação, auto-direção, universalismo, benevolência, tradição, conformidade e segurança.

Esses tipos foram verificados em estudos com amostras de diversas culturas (Schwartz, 1992; Schwartz \& Bilsky, 1987; Schwartz \& Bilsky, 1990). A projeção das intercorrelações entre os valores numa figura geométrica bidimensional, obtida através de uma Guttman-Lingoes Smallest Space Analysis (Canter, 1985; Davison, 1983; Guttman, 1968), mostrou que os diversos domínios se organizam em função de relações de compatibilidade entre alguns valores, e de conflitos entre outros. Neste sentido, numa dimensão se opuseram a abertura à mudança (fruto das relações de compatibilidade entre os domínios da auto-direção e da estimulação) e conservação (resultante da compatibilidade entre segurança, tradição e conformidade), expressando o conflito entre: valorizar a mudança (a independência no pensamento e nas ações) versus a manutenção do status quo. Na outra dimensão, a auto-transcendência (formada por uma relação de compatibilidade entre universalismo e benevolência) foi oposta à auto-promoção (constituída pelos valores do poder e da realização), traduzindo o conflito entre promover o bem-estar coletivo e valorizar o domínio sobre os outros e a obtenção do sucesso pessoal. O hedonismo compartilhou elementos tanto de abertura à mudança quanto de auto-promoção. A existência dessas dimensões foi constatada em várias culturas (Schwartz, 1994), embora algumas variações tenham sido verificadas em função do desenvolvimento cognitivo dos indivíduos (Menezes \& Campos, 1997).

Numa perspectiva mais sociológica, Inglehart (1971, 1977) propôs uma taxonomia que diferencia dois grupos de valores: os materialistas e os pós-materialistas. O interesse desse autor era analisar as mudanças culturais, a longo prazo, em sociedades industrializadas. Para tanto, ele derivou doze indicadores da hierarquia de Maslow (1954) sobre as necessidades. A metade descreve valores de orientação materialista que se relaciona com a necessidade de segurança física e econômica dos indivíduos; a outra metade representa necessidades de auto-realização, estética e intelectual, sendo chamada de pós-materialista, e que revela preocupações com a qualidade de vida, a realização no trabalho, a vida comunitária e a justiça social. O autor acrescenta, ainda, que apenas as sociedades que tenham atingido um certo grau de satisfação das necessidades materiais e de segurança priorizariam os valores pós-materialistas. Essas hipóteses foram submetidas à prova em diversos estudos, tanto de ordem transcultural (Flanagan, 1987; Inglehart, 1991; Vala, 1994), quanto de ordem intracultural (Bean \& Papadakis, 1994), com a utilização de vários instrumentos (Braithwaite, Makkai \& Pittelkow, 1996). Posteriormente, Inglehart (1994), re-interpretando as teses de Weber (1904-5/1994) sobre o desenvolvimento do capitalismo, considera que nos valores materialistas efetuase uma passagem dos valores religiosos espiritualistas a uma concepção de um estado laico e materialista. Nos valores materialistas se encontraria a diferenciação entre valores espirituais e valores materiais.

$\mathrm{Na}$ perspectiva psicossociológica (Billig, 1987; Camino, 1996; Deschamps, 1989; Doise, 1976, 1982) os valores são definidos como qualidades socialmente desejáveis, que compõem os repertórios representacionais produzidos por indivíduos e grupos em suas relações intergrupais. Esses repertórios desenvolvem-se nas lutas ideológicas pelo poder (Deschamps \& Devos, 1993; Lima, 1997; Pereira \& Camino, 1999; Pereira, Lima \& Camino, 1997) e fazem parte da construção social da realidade (Berger \& Luckmann, 1973). Essa abordagem está em consonância com a proposta de Maio e Olson (1998) - a de que a idéia de truísmos culturais como enunciados óbvios e amplamente compartilhados pelos grupos sociais seria uma metáfora válida para descrever os valores - e inspirou uma série de pesquisas desenvolvidas na Paraíba sobre a configuração da estrutura e do conteúdos dos sistemas de valores de estudantes universitários, assim como a relação desses sistemas com as atitudes políticas dos estudantes.

\section{Estudo 1}

\section{A Estrutura e o Conteúdo dos Sistemas de Valores de Estudantes Universitários de João Pessoa}

Torres (1992) desenvolveu um estudo sobre os valores escolhidos por estudantes universitários da cidade de João 
Pessoa para a construção de uma sociedade ideal e sobre a influência dessas escolhas no comportamento político. A autora perguntou aos estudantes sobre o grau de importância de nove valores, retirados da escala de Rokeach (1973), na organização de uma sociedade ideal, observando que esses constituíam dois sistemas: o de valores democráticos (indicado pela igualdade, liberdade, honestidade, justiça, fraternidade e participação) e o de valores autoritários (formado pela obediência, autoridade e religiosidade). Constatou, também, que uma maior adesão ao sistema autoritário implicava maior rejeição ao socialismo e menores índices de simpatia partidária, embora não se tenha constatado nenhuma relação entre o sistema democrático e as atitudes políticas dos estudantes.

Considerando que os valores utilizados por Torres (1992) limitam-se à arena política, Lima e Camino (1995) elaboraram uma lista mais ampla, com 17 valores - que contempla outras dimensões da vida, possíveis de relacionar à política -, e aplicaram-na a estudantes de psicologia. Os resultados de uma análise dos componentes principais mostraram que esses valores se organizam em cinco sistemas: o do bem-estar individual (conforto, prazer e auto-realização), o do bem-estar econômico (lucro, riqueza e autoridade), o religioso (temor a Deus, religiosidade e salvação da alma), o igualitário (igualdade, alegria, cooperação e fraternidade) e o libertário (liberdade, justiça, honestidade e participação). Diferente do esperado por Rokeach (1973), esses dois últimos sistemas não se opuseram, mas se correlacionaram positivamente entre si e com o do bem-estar individual, indicando, assim, uma possível configuração de valores vinculados ao bem-estar social. Os autores verificaram também que a adesão aos sistemas igualitário e libertário relaciona-se com a participação política e com o posicionamento à esquerda no espectro político. Finalmente, constataram que aqueles que aderem mais aos valores do bem-estar individual e menos a valores religiosos e econômicos possuem um certo nível de identificação partidária.

Num terceiro estudo, Pereira, Lima e Camino (1997) acrescentaram oito novos valores à escala anterior, valores que foram considerados importantes por universitários da Paraíba num estudo piloto. Uma análise fatorial dos escores obtidos com os 25 valores confirmou a existência de cinco sistemas: a) bem-estar social, que reuniu os valores dos sistemas libertário e igualitários verificados por Lima e Camino (1995); b) bem-estar individual; c) bem-estar profissional; d) religioso; e) bem-estar econômico. Além disso, mostrou que, de fato, a adesão a valores econômicos e religiosos relaciona-se negativamente com o vínculo de estudantes universitários a instituições democráticas, tais como: participação política, simpatia partidária e disposição de votar.

O tipo de análise empregado nesse conjunto de estudos não permite encontrar as dimensões de ordem superior que estruturam estes diversos sistemas de valores. Portanto, decidiu-se realizar um estudo com este objetivo. O estudo, a partir da escala desenvolvida por Pereira, Lima e Camino (1997), analisa as dimensões subjacentes à estrutura e ao conteúdo dos sistemas de valores de estudantes universitários da cidade de João Pessoa. Para a interpretação dessas dimensões serão utilizadas a distinção entre valores materialistas e pós-materialista (Inglehart, 1977, 1991), e a organização proposta por Schwartz (1992) em valores de abertura à mudança versus conservação e de auto-transcendência versus autopromoção.

\section{Participantes}

\section{Método}

Foram aplicados 350 questionários numa amostra de estudantes do Campus I da Universidade Federal da Paraíba. Os sujeitos apresentaram idade média de 22,5 anos e desvio padrão igual a 4,45.

\section{Instrumento}

Para medir os valores foi utilizada a escala desenvolvida por Pereira, Lima e Camino (1997), que contém 25 valores, a saber: alegria, amor, auto-realização, autoridade, competência, conforto, cooperação, dedicação ao trabalho, fraternidade, hierarquia, honestidade, igualdade, justiça, liberdade, lucro, ordem, participação, prazer, realização profissional, religiosidade, responsabilidade, riqueza, salvação da alma, status e temor a Deus. Os estudantes atribuíram uma nota variando de 1 a 10 em função da importância de cada um destes valores para a construção de uma sociedade ideal.

\section{Procedimentos}

Os questionários, respondidos individualmente, foram aplicados em salas de aula definidas através de sorteio.

\section{Resultados e Discussão}

A configuração do sistema de valores dos estudantes foi obtida com o uso de duas técnicas estatísticas: A Hierarchical Cluster Analysis - HCA - e a Multidimensional Scaling-MDS. A HCA utiliza medidas de dissimilaridades (distâncias euclidianas) entre as variáveis para a construção de grupos ou clusters de variáveis. Foi utilizado o critério de agrupamento de distâncias desenvolvido por Ward (1963). Já na MDS as distâncias euclidianas podem ser 
consideradas análogas ao conceito de distância psicológica da Teoria de Campo de Kurt Lewin (1951/1978), que proporciona um tipo de mapa mental que oferece uma interpretação em termos de dimensões. O grau de perfeição do ajustamento das variáveis às dimensões obtidas é medido pelo Coeficiente de Stress (Abelson, 1967). O uso da HCA juntamente com a MDS permite uma interpretação mais apurada dos resultados (Kruskal $\&$ Wish, 1978). Coeficientes $r$ de Pearson foram calculados para a análise das intercorrelações entre os diversos sistemas de valores, e alfas de Cronbach (1951) foram usados na verificação da consistência interna das escalas. Todas as análises foram feitas no SPSS-8,0.

A HCA aplicada ao grau de importância atribuída aos valores para a construção de uma sociedade ideal revela a formação de três agrupamentos (clusters). Os valores temor a Deus, religiosidade e salvação da alma, formam o conjunto de valores religiosos. Já status, riqueza, lucro, autoridade e hierarquia constituem o conjunto de valores do bem-estar econômico. Esses dois sistemas se diferenciam de um grande conjunto homogêneo, constituído por: valores do bem-estar social (igualdade, liberdade, fraternidade, ordem, participação, justiça e honestidade), valores vinculados ao bem estar individual (prazer, conforto, auto-realização, alegria e amor) e valores do bem-estar profissional (realização profissional, dedicação ao trabalho, cooperação, competência e responsabilidade). Esses resultados encontram-se nos quadros pontilhados que envolvem os valores na Figura 1.

Os resultados da MDS mostram (Figura 1) os valores dos estudantes distribuídos em função de duas dimensões (stress $=0,06$ e $\left.R^{2}=0,99\right)$. Na primeira, que poderia ser aproximada à distinção proposta por Inglehart (1977) entre valores materialistas e pós-materialistas, os dois sistemas de valores ligados a interesses econômicos e religiosos (sistemas denominados respectivamente de bem-estar econômico e religioso) se diferenciam de um grande conjunto de valores constituído pelos sistemas do bem-estar social, do bem estar individual e do bemestar profissional.

A segunda dimensão pode ser interpretada a partir da outra distinção proposta por Inglehart (1994) entre valores religiosos e valores materiais. Os valores pósmaterialistas encontram-se numa posição intermediária, bem no valor 0 (zero) dessa dimensão, indicando assim que não participam dela. Portanto, consideraram-se, para futuras análises, três sistemas de valores: o materialista, o religioso e o pós-materialista (estes sistemas obtiveram alfas $=0,92,0,88$ e 0,91, respectivamente, na análise da consistência interna das escalas).

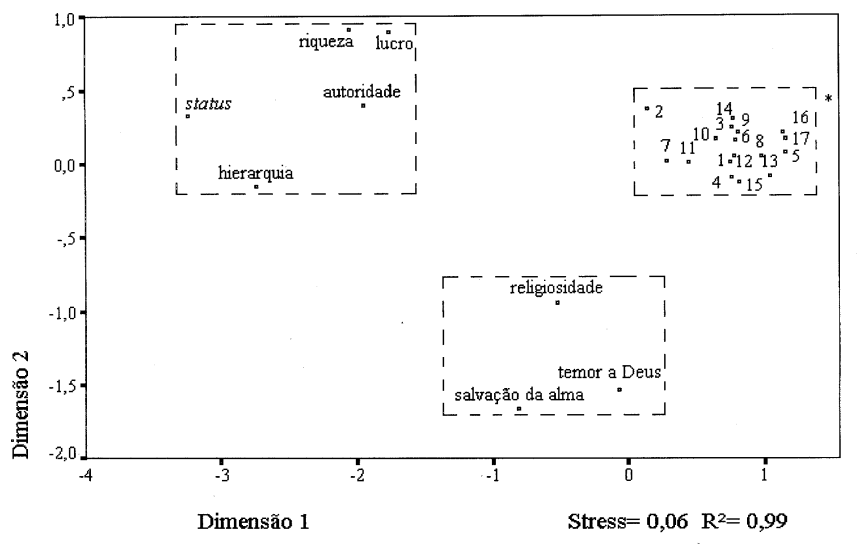

Figura 1. Agrupamentos dos valores para a construção de uma sociedade ideal

*Os valores contidos neste quadro são os seguintes:

1-participação; 2-prazer; 3-liberdade; 4-alegria; 5-honestidade; 6-cooperação; 7-conforto; 8-igualdade; 9-auto-realização; 10dedicação; 11-ordem; 12-competência; 13-amor; 14-realização profissional; 15-fraternidade; 16-justiça; 17-responsabilidade.

A comparação entre esses resultados e os obtidos por Inglehart (1977) exige uma reflexão cuidadosa das interpretações propostas para a oposição entre valores materialistas e pós-materialistas. A hipótese principal desse autor é a de que as sociedades que ainda não resolveram problemas sociais básicos, tais como estabilidade econômica, segurança e organização política, tendem a valorizar as metas materialistas, enquanto aquelas que atingiram um certo grau de resolução desses problemas priorizam valores pós-materialistas. Assim, em diversos estudos realizados nos Estados Unidos e na Europa (Inglehart, 1991), a adesão a valores pós-materialistas apresentou correlação negativa com a valorização do sistema materialista. Já neste estudo, as correlações entre os sistemas são positivas: materialista versus pós-materialista $(r=0,25 ; p<0,001)$; materialista versus religioso $(r=0,65$; $p<0,001)$; e religioso versus pós-materialista $(r=0,32 ; p<$ $0,001)$.

Contudo, embora os valores pós-materialistas estejam difundidos em diferentes culturas (Inglehart, 1994), nos países em via de desenvolvimento, onde os problemas sociais básicos ainda não foram solucionados, os valores materialistas ainda são amplamente compartilhados. Nesses países é provável que, para a construção de uma sociedade ideal, a adesão a valores pós-materialistas não implique, necessariamente, a redução da importância atribuída ao sistema materialista (Pereira \& Camino, 1999). De fato, as correlações positivas verificadas entre esses sistemas indicam que os estudantes tanto podem 
considerar importantes os valores que descrevem o pósmaterialismo, como podem valorizar a autoridade, a hierarquia, a riqueza e o status.

No que concerne à comparação dos resultados deste estudo com a teoria de Schwartz (1992, 1994, 1996), pode-se destacar a semelhança de conteúdo que o sistema materialista (autoridade, riqueza, lucro, status e hierarquia) mantém com os valores do poder (poder social, autoridade, riqueza, reconhecimento social e preservador da minha imagem pública). Já o conteúdo do sistema pós-materialista encontrado neste estudo (igualdade, liberdade, fraternidade, ordem, participação, justiça, honestidade, prazer, conforto, auto-realização, alegria, amor, realização profissional, dedicação, cooperação, competência e responsabilidade) assemelha-se aos dos tipos motivacionais do universalismo (justiça social, igualdade, protetor do ambiente, união com a natureza, um mundo de beleza, aberto, sabedoria, um mundo em paz, e harmonia interior), da benevolência (honesto, amor maduro, prestativo, leal, responsável, amizade verdadeira e sentido da vida), e da auto-direção (liberdade, independente, criatividade, curioso, escolhendo minhas metas e auto-respeito).

Não é de se estranhar que o conteúdo do sistema pós-materialista seja formado pela junção de vários tipos de valores, uma vez que em diversos estudos (Menezes \& Campos, 1997; Tamayo \& Schwartz, 1993) os valores de benevolência e de universalismo não se diferenciaram. Entretanto, a presença de valores de auto-direção neste sistema pode ser compreendida quando se considera a perspectiva sociológica de Inglehart (1994), para a qual os valores pós-materialistas representam preocupações estéticas, intelectuais e de auto-realização, além de traduzir o interesse pela qualidade de vida, pela realização no trabalho, pela vida comunitária e pela justiça social. Além disso, Helkama, Uutela e Schwartz (1992) confrontaram a dicotomia de valores materialistas-pós-materialistas com a tipologia de Schwartz (1992), mostrando que os indicadores de pós-materialismo associam-se a valores de universalismo, e os de materialismo aos de segurança.

Já no que se refere ao sistema religioso, embora seu conteúdo (religiosidade, temor a Deus e salvação da alma) não apresente uma clara similaridade empírica com nenhum dos tipos motivacionais, ele mantém uma semelhança conceitual com os valores da conservação encontrados em diversas culturas por Schwartz (1992) e, no Brasil, por Tamayo e Schwartz (1993), notadamente no que se refere aos tipos motivacionais da conformidade (obediente, respeitoso para com os pais e idosos, autodisciplina e polidez) e da tradição (devoto, ciente dos meus limites, humilde, respeito pela tradição, moderado e despreendido). Em ambos os casos, esses valores descrevem um estilo de vida baseado na submissão e na auto-restrição dos indivíduos para preservar o status quo da sociedade. Neste sentido, Inglehart (1994) verificou que, em diferentes culturas, os valores religiosos aparecem fortemente relacionados aos da tradição e da obediência, configurando-se em um único fator. Ademais, os dados deste estudo corroboram os de pesquisas realizadas na Paraíba que mostraram que o conteúdo do sistema religioso reflete a importância da religião na vida desses estudantes (Lima, 1997; Lima \& Camino, 1995; Pereira, Lima \& Camino, 1997). A avaliação de diversos sistemas é importante, pois a preferência por um ou outro sistema de valores influencia diferentemente variáveis políticas, tais como: a disposição para contato social com grupos minoritários (Sagiv \& Schwartz, 1995), o voto num determinado candidato ou partido político (Barnea \& Schwartz, 1998), as atitudes e comportamentos de um modo geral (Homer \& Kahle, 1988) e as atitudes políticas em particular (Rokeach, 1973).

Existe uma clara distinção entre os resultados deste estudo e os de Schwartz (1992). Este autor, baseado num conjunto de necessidades universais e individuais (Kluckhohn, 1968; Parsons, 1957), afirma que os diversos valores se organizam em função de relações de compatibilidade e conflitos entre eles. Para o autor, uma primeira dimensão contrapõe os valores da autotranscendência aos da auto-promoção, enquanto numa segunda dimensão apareceria o conflito entre aderir a valores de conservação e priorizar os domínios motivacionais da abertura à mudança. De fato, a figura geométrica produzida pela Smallest Space Analysis de Guttman (1968) ou pela MDS de Kruskal e Wish (1978) coloca os sistemas em lados opostos. Essa localização não implica, necessariamente, uma oposição real entre valores, pois estatísticas baseadas em medidas de similaridade ou dissimilaridade forçam uma oposição que não se dá na mente das pessoas (Lima, 1997). Ao contrário, as correlações positivas verificadas entre os sistemas de valores, neste estudo, sugerem um truísmo cultural, ou seja, que as pessoas de fato valorizam os valores. As diferenças entre valores ocorrem tanto no grau de preferência como nos tipos de contexto onde as preferências são efetivadas. Neste sentido, todos os valores são crenças (Rokeach, 1979b), concepções (Schwartz, 1994), que são desejáveis socialmente (Deschamps \& Devos, 1993) e que se configuram em forma de repertórios representacionais (Pereira, Lima \& Camino, 1997). A partir da concepção de valores como construtos sociais, e não como decorrentes de uma hierarquia de necessidades, parece difícil conceber que, por serem 
amplamente compartilhados pelo grupo social, possam ser opostos na sua estrutura. O que pode ocorrer é que sejam preferidos uns aos outros, dependendo do contexto. Além disso, a cisão entre valores é insustentável, pois todos eles são sociais na medida em que são produzidos nas interações entre os homens (Beattie, 1980) e são amplamente compartilhados por estes (Maio \& Olson, 1998). Assim, os sistemas de valores, considerados como repertórios representacionais, não se opõem, mas se correlacionam positivamente (Billig, 1987).

Fica uma pergunta a responder: como os sistemas de valores dos estudantes da Paraíba influenciam suas atitudes políticas? Planejou-se um segundo estudo para responder a esta questão.

\section{Estudo 2 Sistemas de Valores e Atitudes Democráticas em Estudantes Universitários de João Pessoa}

Este estudo analisa, inicialmente, a estrutura e o conteúdo dos sistemas de valores de estudantes de uma universidade privada, esperando-se encontrar as mesmas dimensões verificadas no primeiro estudo. Num segundo momento, verificam-se as relações entre os sistemas de valores e as atitudes políticas dos estudantes. Mas quais atitudes? Uma análise do contexto político atual permitirá avaliar os temas centrais da política no país.

Os países da América Latina passaram, a partir da década de 60, por um período de mais de 20 anos sob a vigência de ditaduras militares que limitaram os direitos de cidadania dos indivíduos. Nesse período, apareceram vários movimentos sociais, entre os quais o estudantil, que funcionava como foco de resistência contra as práticas autoritárias dos militares (Lhullier, 1992, 1996, 1997). Com a abertura política, na década de 80 , iniciou-se um processo de democratização caracterizado pelo discurso antiditatorial (Lechner, 1994). Nesse momento, como tinha sido observado em outros países, a democracia passou a estar associada não só ao bom funcionamento de um país, como ao pleno desenvolvimento da personalidade dos indivíduos (Giner, 1986; Macpherson, 1978). Contudo, a abertura política, caracterizada principalmente pela implantação do processo eleitoral, não trouxe, nem ao Brasil e nem a América Latina, melhoria material, cultural ou política, produzindo uma certa apatia e desconfiança da população em relação às instituições democráticas (Camino, Torres \& Da Costa, 1995; D’Adamo \& Beaudoux, 1995; De Riz, 1994), o que colocou em risco tanto a adesão aos princípios fundamentais da democracia (Offe, 1985), quanto o atual processo de redemocratização (Baquero, 1994).

Construi-se, assim, uma oposição entre a crença na democracia como essencial ao desenvolvimento do indivíduo e da sociedade e a descrença na utilidade do voto (esta última estava aliada à crença na eficácia da ditadura). Embora não exista um consenso quanto ao significado da democracia (Bobbio, 1986; 1991; 1992; Rosanvallon, 1996; Rouquié, 1985; Schmitter, 1997; Touraine, 1996), a oposição percebida entre desenvolvimento sócio-econômico e voto atinge a definição formal de democracia como um sistema político que se contrapõe a qualquer forma autoritária de governar (Bobbio, 1993b; Macpherson, 1978). De fato, pesquisas realizadas na Paraíba (Camino, Torres \& Da Costa, 1995) mostraram que menos da metade dos estudantes universitários estavam dispostos a votar caso o voto não fosse obrigatório. No seu estudo sobre a participação de estudantes universitários nas eleições de 1988, 1990 e 1992, Torres (1992) observou que menos da metade dos estudantes possuem simpatia partidária definida e sabem situar-se na dimensão clássica esquerdadireita. $\mathrm{Na}$ população essas tendências são maiores, de modo que $60 \%$ não estão dispostos a votar, 64\% não têm simpatia partidária e $84 \%$ não participariam de nenhum movimento de protesto sócio-político (Gouveia, França, Da Costa \& Camino, 1997). Assim, o problema essencial das atitudes políticas na América Latina parece não passar pela oposição direita (Liberdade) e esquerda (Igualdade), mas pela relação entre a estabilidade econômica e a democracia.

Neste sentido é que se coloca como importante a análise do papel de fatores sociais, tal como os valores, no desenvolvimento das atitudes democráticas. De fato, pesquisas realizadas na Paraíba (Lima, 1997; Lima \& Camino, 1995; Pereira \& Camino, 1999; Pereira, Lima \& Camino, 1997) mostram que os estudantes que priorizavam mais fortemente os valores materiais e religiosos não estavam vinculados, através da simpatia partidária, às instituições políticas e não participavam em atividades de protesto sócio-político. Assim, espera-se que a prioridade atribuída a esses valores esteja associada a uma atitude negativa em relação à democracia. Por outro lado, a adesão aos valores pós-materialistas (Inglehart, 1994) estará relacionada positivamente com as atitudes democráticas, pois o discurso democrático atual apresenta-se ligado à defesa dos valores que constituem esse sistema: liberdade, igualdade, bem-estar individual e social (Iñíquez \& Vázquez, 1995).

\section{Participantes}

\section{Método}

A amostra foi composta por 200 estudantes de ambos os sexos do Centro Universitário de João Pessoa (CUNJPE), os quais apresentaram idade média de 26,2 anos e desvio padrão igual a 7,85. 


\section{Instrumentos}

Para medir os valores, foi utilizada a mesma escala aplicada no Estudo 1. Nela, os estudantes atribuíram a cada um dos valores uma nota variando entre 1 e 10, considerando a importância deles para a construção de uma sociedade ideal para se viver. Já a atitude democrática foi medida através do posicionamento dos estudantes em relação às seguintes afirmações: "Só num país democrático as pessoas poderão se desenvolver plenamente"; "A democracia é essencial para o bom funcionamento de um país"; "É melhor uma ditadura competente que uma democracia incompetente"; "As eleições não são necessárias para se ter um bom governo". Os estudantes indicaram seu grau de concordância para cada uma das afirmações numa escala tipo Likert (1970), que varia de 1 (discordo totalmente) a 5 (concordo totalmente).

\section{Resultados e Discussão}

A estrutura do sistema de valores dos estudantes foi analisada com o auxílio das duas técnicas estatísticas utilizadas no primeiro estudo. Coeficientes $r$ de Pearson indicaram a magnitude e a direção das correlações entre os sistemas de valores. Foi aplicada uma análise fatorial (extração Principal-Axis Factoring) para avaliar a dimensionalidade da escala de democracia. A consistência interna dos sistemas de valores e da escala de democracia foi obtida calculando os alfas de Cronbach (1951). Por fim, a relação entre os sistemas de valores e a atitude democrática foi verificada através de uma regressão múltipla pelo método stepwise.

A HCA, aplicada aos escores atribuídos pelos estudantes aos valores para a construção de uma sociedade ideal, reproduz os resultados obtidos no primeiro estudo, com a classificação dos valores em três clusters. Os valores hierarquia, autoridade, status, riqueza e lucro constituem o conjunto de valores com características materiais e econômicas. Os valores temor a Deus, religiosidade e salvação da alma formam o conjunto de valores fundamentalmente religiosos. Esses dois sistemas também se diferenciam de um grande conjunto homogêneo constituído por valores do bem-estar social (igualdade, liberdade, fraternidade, ordem, participação, justiça e honestidade), por valores vinculados ao bemestar individual (prazer, conforto, auto-realização, alegria e amor) e por valores concernentes ao bem-estar profissional (realização profissional, dedicação ao trabalho, cooperação, competência e responsabilidade). Estes resultados se encontram no interior dos quadros pontilhados na Figura 2.
Os resultados da MDS (Figura 2) mostram que duas dimensões foram necessárias para organizar os valores $\left(\right.$ stress $=0,08$ e $\left.R^{2}=0,98\right)$. Como esperado, a distinção proposta por Inglehart (1991) entre valores materialistas e pós-materialistas, reaparece na primeira dimensão. $\mathrm{O}$ conjunto de valores ligados a interesses econômicos e materiais diferencia-se de um grande conjunto de itens formado por valores do bem-estar social, por valores vinculados ao bem estar individual e por valores do bemestar profissional. Os valores religiosos, por estarem situados no ponto 0 (zero) nas coordenadas da dimensão, não podem ser considerados como constituinte desta.

Já a segunda dimensão, material-espiritual, separa os valores religiosos dos econômicos e materiais. Os valores do sistema pós-materialista encontram-se no ponto 0 (zero) desta dimensão, não participando dela. Assim, para a organização de uma sociedade ideal, os estudantes classificam seus valores em função de três sistemas: o materialista, o religioso e o pós-materialista. Esses sistemas obtiveram alfas $=0,74,0,77$ e 0,91 , respectivamente, na

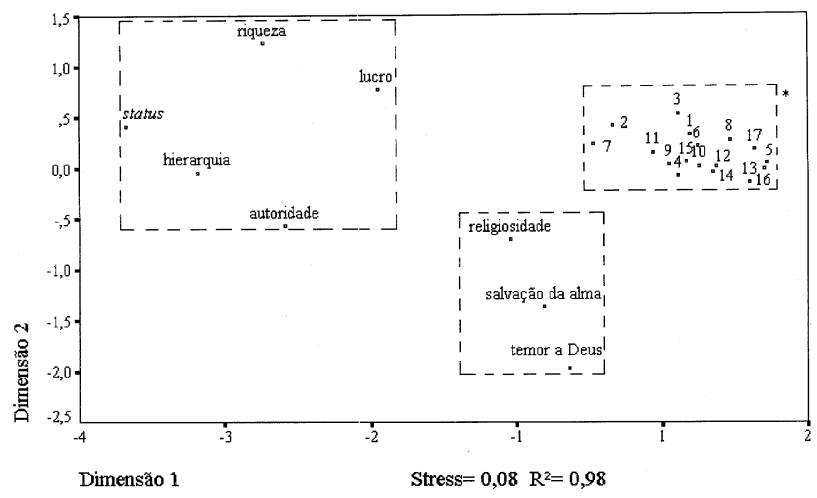

Figura 2. Agrupamentos dos valores para a construção de uma sociedade ideal por estudantes de uma universidade privada

*Os valores contidos neste quadro são os seguintes:

1-participação; 2-prazer; 3-liberdade; 4-alegria; 5-honestidade; 6-cooperação; 7-conforto; 8-igualdade; 9-auto-realização; 10dedicação; 11-ordem; 12-competência; 13-amor; 14-realização profissional; 15-fraternidade; 16-justiça; 17-responsabilidade.

análise da consistência interna dos itens. Mais uma vez, observou-se que as correlações entre os sistemas são positivas: materialista versus pós-materialista $(r=0,27 ; p<$ $0,001)$; materialista versus religioso $(r=0,39 ; p<0,001)$; religioso versus pós-materialista $(r=0,34 ; p<0,001)$.

A análise fatorial aplicada ao grau de concordância dos estudantes com as quatros afirmações usadas para avaliar a atitude democrática (Tabela 1) mostra que os 
quatro itens constituem um fator que explica $31 \%$ da variância total. Como esperado, o fator traduz a oposição entre avaliar a democracia como essencial para o bom funcionamento de um país, onde as pessoas poderão se desenvolver plenamente e concordar que é melhor uma ditadura competente do que uma democracia incompetente, e que as eleições não são necessárias para se ter um bom governo. A dimensão democraciaditadura, além de ter sido encontrada em estudos sobre autoritarismo de estudantes universitários (Lhullier, 1996), expressa uma atitude formulada a partir de uma postura anti-ditatorial (Lechner, 1994) e traduz a noção fundamental da democracia como um sistema político que se contrapõe a qualquer forma autoritária de governar (Bobbio, 1993b; Macpherson, 1978). Pode-se afirmar que os resultados da análise fatorial mostram uma certa concepções políticas sobre o significado da democracia que, por definição, é complexo e multifacetado (Bobbio, 1986; 1991; 1992; Rosanvallon, 1996; Rouquié, 1985; Schmitter, 1997; Touraine, 1996).

Utilizando esta escala que avalia a atitude dos estudantes frente à dimensão democracia-ditadura, interessava verificar a relação dos valores com a presente atitude política dos estudantes. Os resultados da regressão múltipla $\left(R^{2}=0,06 ; F=5,764 ; p<0,01\right)$ mostram que a adesão ao sistema de valores pós-materialista se relaciona positivamente com a atitude frente à democracia $(b=0,20$; $p<0,01)$, enquanto que o sistema religioso apresenta uma associação negativa com essa atitude $(b=-0,22 ; p<0,01)$. De fato, Inglehart (1991) mostra que os valores pósmaterialistas descrevem um estilo de vida democrático que se caracteriza pela inserção do indivíduo nas decisões

Tabela 1. Resultados da Análise Fatorial Aplicada ao Grau de Concordância dos Estudantes com os Itens que Compõem a Escala de Democracia

Escala de Democracia

A democracia é essencial para o bom funcionamento de um país

Só num país democrático as pessoas poderão se desenvolver plenamente

As eleições não são necessárias para se ter um bom governo

É melhor uma ditadura competente que uma democracia incompetente

Eigenvalue

Variância Explicada

Consistência Interna

Carga Fatoria
0,80
0,55
$-0,33$
$-0,43$

1,24
$31 \%$
$a=0,60$

consistência teórica da escala (validade de construto), embora sua fidedignidade seja apenas razoável $(a=0,60)$. Este coeficiente de fidedignidade indica que a escala apresenta um certo grau de fragilidade. Portanto, faz-se necessário, em futuras investigações, reformular os itens de avaliação do posicionamento democrático dos estudantes. Contudo, deve-se considerar que não era de se esperar obter um coeficiente elevado, uma vez que não se pretendia medir disposições psicológicas, mas políticas e pela valorização da liberdade de expressão. Ademais, a concepção moderna de democracia se fundamenta na prática dos valores que constituem o sistema pós-materialista, tais como: igualdade de oportunidades, liberdade individual, fraternidade, participação e justiça social (D'Adamo \& Beaudoux, 1995; Iñíquez \& Vázquez, 1995).

Também pode-se pensar que a semelhança no conteúdo dos valores do sistema religioso deste estudo

Tabela 2. Resultados da Regressão Múltipla Usada para Analisar a Relação dos Valores com a Atitude dos Estudantes em Relação à Democracia

\begin{tabular}{lccc}
\hline & \multicolumn{2}{c}{ Atitude em Relação à Democracia } \\
Variáveis Antecedentes & Beta & $t$ & $p$ \\
\hline Sistema de Valores Materialistas & $-0,01$ & $-0,066$ & n.s \\
Sistema de Valores Religiosos & $-0,22$ & $-2,89$ & 0,01 \\
Sistema de Valores Pós-materialistas & 0,20 & 2,62 & 0,01
\end{tabular}

Coeficiente de Regressão Múltipla

Explicação da Variabilidade

Teste Estatístico

$$
\begin{aligned}
R & =0,25 \\
R^{2} & =0,06
\end{aligned}
$$

$F(2 / 196)=5,767 ; \mathrm{p}<0,01$ 
com os valores de conservação encontrados por Schwartz (1992), que descrevem um estilo de vida baseado na submissão e na auto-restrição do indivíduo para preservar o status quo da sociedade, explicaria a associação negativa apresentada pelo sistema religioso com as atitudes democráticas. Nesse sentido, Barnea e Schwartz (1998) mostram que o voto em partidos políticos de Israel está determinado por duas dimensões: liberalismo clássico (formada por partidos que defendem uma posição democrática) e religiosidade (constituída por partidos que enfatizam o autoritarismo para a manutenção da ordem social). Assim, numa função discriminante, os valores de conservação se relacionaram negativamente com o voto em partido liberais, enquanto que em outra função se correlacionaram positivamente com o voto em partidos de ideologia religiosa. Além disso, pesquisas realizadas na Paraíba (Lima \& Camino, 1995; Pereira Lima \& Camino, 1997) mostraram que a adesão a valores religiosos implica a diminuição do vínculo de estudantes universitários com instituições democráticas, como a simpatia partidária e a disposição a votar.

A ausência de relação negativa entre a atitude democrática e a adesão ao sistema materialista de valores contraria as hipóteses previamente formuladas e os postulados de Inglehart (1991). Este autor mostrou que nas sociedades economicamente estáveis a valorização de metas materiais se opõe as pós-materiais. De fato, se os valores pós-materialistas aparecem ligados à democracia, era de se esperar que os materialistas se relacionassem negativamente com a atitude democrática. Contudo, nos países em via de desenvolvimento a oposição entre esses valores pode não aparecer, como revelam as correlações positivas entre os sistemas de valores nos dois estudos realizados. Assim, no contexto paraibano, a atitude negativa dos estudantes em relação à democracia não passa pela valorização das metas materialistas, mas sim pela adesão ao sistema de valores religiosos, como mostraram os resultados.

\section{Conclusões}

Nos dois estudos, as análises de Clusters (HCA) e Multidimensional (MDS) mostram que, para os universitários da cidade de João Pessoa, os valores que servem de base para uma sociedade ideal se organizam em três sistemas claramente demarcados: o religioso, o materialista e o pós-materialista. $\mathrm{O}$ sistema religioso se caracteriza por integrar valores espirituais: temor a Deus, religiosidade e salvação da alma. O sistema materialista reúne valores que propõem a ganância (riqueza e lucro) e a estratificação social (status, hierarquia e autoridade) como objetivos a conseguir numa sociedade ideal. Finalmente, o sistema pós-materialista integra, como proposto por Inglehart (1991), um conjunto de subsistemas de valores que vão de valores sociais (igualdade, liberdade, fraternidade, ordem, participação, justiça e honestidade) à valores individuais (prazer, conforto, auto-realização, alegria e amor), passando pelos valores concernentes ao trabalho e ao bem-estar profissional (realização profissional, dedicação ao trabalho, cooperação, competência e responsabilidade).

Tentou-se, inicialmente, explicar esses resultados a partir das teorias de Schwartz (1992) e Inglehart (1977, 1991), mas, de fato, algumas características dos dados obtidos sugeriram a necessidade de uma explicação dos valores em termos de repertórios representacionais e não em termos de sistemas motivacionais. Assim, num primeiro momento, percebeu-se que existem fortes semelhanças entre os resultados dos dois estudos e os conteúdos propostos por Schwartz (1992), embora na configuração e na estruturação apareçam diferenças claras. Constataram-se também semelhanças entre os dados obtidos e as configurações propostas por Inglehart (1994). Mas a estrutura desses dados também difere da proposta por este último autor.

No que se refere ao conteúdo dos sistemas, uma certa semelhança pode ser assinalada entre eles e os tipos motivacionais hipotetizados por Schwartz (1992): o religioso assemelha-se aos valores de conservação (fundamentalmente aos da tradição e conformidade), pois ambos traduzem um estilo de vida fundamentado no autocontrole dos impulsos que visam à quebra da harmonia social e a manutenção do status quo; o sistema materialista se assemelha ao do poder social; o pósmaterialista aglutinou valores de universalismo, de benevolência e de auto-direção. Contudo, para que essa semelhança seja definitivamente comprovada, é necessária a realização de uma nova investigação com a finalidade de fazer uma validação convergente entre o questionário de valores utilizado por Schwartz (1992) e a escala usada nos dois estudos apresentados aqui.

A complexidade do sistema denominado de pósmaterialista, que reúne valores socio-políticos com valores individuais, exige uma reinterpretação de certas proposições clássicas no que concerne aos valores. Assim, os resultados dos dois estudos realizados não sustentam as diferenças tanto entre valores políticos e não políticos, como no interior dos valores políticos, entre igualdade e liberdade, tal como estabelecida por Rokeach (1973). Constatou-se, entretanto, que o sistema pós-materialista inclui tanto valores políticos (liberdade, igualdade, fraternidade) como valores não políticos (alegria, amor, 
conforto). Estas diferenças explicam-se principalmente pelas diferentes conjunturas políticas onde foram obtidos os dados. Os sujeitos dos estudos de Rokeach (1973) traduzem, na oposição entre liberdade e igualdade, o panorama da guerra fria, enquanto que os sujeitos dos dois estudos desenvolvidos aqui vivem a situação criada após a derrubada do muro de Berlim. Nestes estudos não se confirma também a diferença entre valores individuais e valores coletivos como proposto por Schwartz (1992) e por Hofstede (1980), dado que o sistema pós-materialista inclui tanto valores individualistas (competência, auto-realização) como coletivistas (fraternidade, cooperação).

Todavia, a diferença encontrada entre as dimensões verificadas por Schwartz (1992) e os resultados dos estudos apresentados neste artigo pode dever-se ao fato de que naquelas pesquisas era solicitado aos sujeitos que avaliassem os valores em função da importância de cada um deles como "um princípio orientador em minha vida", enquanto que nestes era solicitado aos estudantes que classificassem os valores considerando a importância deles para construção de uma sociedade ideal para se viver. Assim, enquanto nos primeiros as avaliações se davam em função da organização da vida pessoal dos entrevistados, nestes o registro avaliativo remete a uma dimensão macro-social onde a dimensão política pode ter contribuído para o rompimento da oposição ente as dimensões individual e social.

Alguns autores (Lima, 1997; Vala, 1993) destacam que a "cisão" entre valores individuais e sociais pode ser um artefato metodológico que naturaliza uma oposição difícil de ocorrer no contexto sócio-político atual. Ademais, de acordo com a perspectiva teórica adotada neste trabalho, a separação ente valores individuais e sociais é insustentável, pois todos os valores são sociais na medida em que refletem experiências de diferentes grupos sociais e se formam no interior desses através do consenso, da comparação social e da pluralidade de opiniões e de crenças sobre a realidade social (Deschamps \& Devos, 1993; Vala, 1994).

A organização dos valores encontrada nos estudantes de João Pessoa segue a configuração proposta por Inglehart (1994) nos seus últimos trabalhos, mas não no sentido que ele dá ao conceito de estrutura. Para este autor a evolução da sociedade feudal ao capitalismo moderno seria acompanhada por sucessivas mudanças nos valores que teriam dominado a sociedade em suas diferentes fases; as sociedades modernas teriam passado do domínio dos valores religiosos ao dos valores materialistas para, atualmente, se encontrarem sob o domínio do que ele denomina de valores pós-materialistas.
Portanto, na estruturação da hierarquia de valores, os três sistemas se oporiam entre si.

De fato, o conjunto de valores analisados se configura nos sistemas propostos por Inglehart (1991), mas não se estruturam em relações de oposição. Por um lado, não é de estranhar que uma amostra de jovens nordestinos, estudantes universitários, integrem positivamente os três sistemas de valores. Parece verossímil, pois, que num país em desenvolvimento como o Brasil e numa região de profundos contrastes sociais, econômicos e culturais como o Nordeste, a jovem elite possua estes sistemas de valores positivamente relacionados. Por outro lado, na medida em que a perspectiva teórica adotada neste artigo não liga os valores a sistemas de necessidades de motivações, nada impede pensar que numa sociedade possa se construir um repertório de valores positivos que apareçam como contraditórios na perspectiva de outra sociedade. Assim, não se deve pensar que a oposição entre os diversos sistemas expresse, necessariamente, disparidades fundamentais entre os valores (Lima, 1997). A existência constatada de correlações positivas entre os três sistemas mostra uma estrutura constituída fundamentalmente por repertórios representacionais organizados não de maneira antagônica, mas simplesmente de forma hierárquica.

De que maneira os três sistemas de valores influenciam a atitude democrática dos estudantes? Os resultados mostraram que a adesão a valores pós-materialista relaciona-se com uma atitude que descreve a democracia como um sistema de governo essencial para o bom funcionamento de um país, onde as pessoas poderão se desenvolver plenamente. Já a adesão a valores religiosos associa-se à concordância de que é melhor uma ditadura competente do que uma democracia incompetente, e que as eleições não são necessárias para se ter um bom governo. Estes resultados corroboram pesquisas anteriores realizadas na Paraíba, onde se observou que os estudantes universitários que priorizavam os valores religiosos apresentavam baixos índices de participação no processo eleitoral (Torres, 1992), ausência de simpatia partidária (Lima \& Camino, 1995) e não estavam dispostos a votar se o voto não fosse obrigatório (Pereira, Lima \& Camino, 1997).

Finalmente, vários autores (Camino \& Da Costa, 1994; Camino, Torres \& Da Costa, 1995; Lima, 1997) defendem que o estudo da relação entre atitudes políticas e valores sociais deve levar em contar a pertença social dos indivíduos, uma vez que os valores, por serem repertórios representacionais utilizáveis em contextos específicos, traduzem a realidade social específica de cada grupo. A pertença a esses grupos constrói a identidade 
social dos indivíduos (Tajfel, 1981) e estabelece a hierarquia de valores necessária à satisfação dos interesses desses em detrimento aos dos outros grupos (Camino, 1996). Assim, espera-se que o impacto dos valores sobre as atitudes políticas seja mais elevado num contexto onde a saliência das relações intergrupais esteja explícita. Novos estudos estão sendo desenvolvidos na Paraíba com o objetivo de desenvolver essa perspectiva no estudo dos valores.

\section{Referências}

Abelson, R. P. (1967). A technique and a model of multi-dimensional attitude scaling. Em M. Fishbein (Org.), Readings in attitude: Theory and measurement (pp. 349-356). New York: Jonh Wiley e Sons.

Baquero, M. (1994). Os desafios na construção de uma cultura política democrática na América Latina: Estado e partidos políticos. Em M. Baquero (Org.), Cultura política e democracia: Os desafios das sociedades contemporâneas (pp. 26-41). Porto Alegre: UFRGS.

Barnea, M. F. \& Schwartz, S. H. (1998). Values and voting. Political Psychology, 19, 17-40.

Bean, C. \& Papadakis, E. (1994). Polarized priorities or flexible alternatives? Dimensionality in Inglehart's materialism-posmaterialism scale. International Journal of Public Opinion Research, 6, 264-297.

Beattie, J. (1980). Introdução à antropologia social. São Paulo: Companhia Editora Nacional.

Bem, D. J. (1973). Conviç̧̃oes, atitudes e assuntos bumanos. São Paulo: EPU.

Berger, P. L. \& Luckmann, T. (1973). A construção social da realidade. Petrópolis: Vozes.

Billig, M. (1987). Arguing and thinking: A rhetorical approach to social psychology. New York: University Press.

Bobbio, N. (1986). O futuro da democracia: Uma defesa das regras do jogo. São Paulo: Paz e Terra.

Bobbio, N. (1991). Três ensaios sobre a democracia. São Paulo: Cardim \& Alario.

Bobbio, N. (1992). Estado, governo, sociedade: Para uma teoria geral da politica. São Paulo: Paz e Terra.

Bobbio, N. (1993a). Política. Em N. Bobbio, N. Matteucci \& G. Pasquino (Orgs.), Dicionário de política (Vol. 2, pp. 954-962). Brasília: UNB.

Bobbio, N. (1993b). Democracia. Em N. Bobbio, N. Matteucci \& G. Pasquino (Orgs.), Dicionário de politica (Vol. 1, pp. 319-329). Brasília: UNB.

Bobbio, N. (1994). Liberalismo e democracia. São Paulo: Brasiliense.

Bond, M. H. (1988). Finding universal dimensions of individual variation in multicultural studies of values: The Rokeach and Chinese value survey. Journal of Personality and Social Psychology, 49, 250-264.

Bottomore, T. (1979). Introdução à Sociologia. Rio de Janeiro: Zahar.

Braithwaite, V. \& Law, H. G. (1985). Structure of human values: Testing the adequacy of the Rokeach Value Survey. Journal of Personality and Social Psychology, 49, 250-263.

Braithwaite, V., Makkai, T. \& Pittelkow, Y. (1996). Inglehart's materialismpostmaterialism concept: Clarifying the dimensionality debate through Rokeach's model of social values. Journal of Applied Social Psychology, 26, 1536-1555.

Camino, L. (1996). Uma abordagem psicossociológica no estudo do comportamento político. Psicologia e Sociedade, 8, 16-42.

Camino, L. \& Da Costa, J. B. (1994). A participação política do adolescente: Indicação de uma abordagem psicossocial a partir da noção de identidade. Temas de Psicologia, 1, 1-16.

Camino, L., Lima, M. E. \& Torres, A. R. (1997). Ideologia e espaço político em estudantes universitários. Em L. Camino, L. Lhullier \& S. Sandoval (Orgs.), Estudos sobre comportamento politico: Teoria e pesquisa (pp. 87-105). Florianópolis: Letras Contemporâneas.
Camino, L., Torres, A. R. \& Da Costa, J. (1995). Voto, identificacion partidaria, identidad social e construccion de la ciudadania. Em O. D'Admo, V. G. Beaudoux \& M. Montero (Orgs.), Psicología de la acción política (pp. 129-142). Buenos Aires: Paidós.

Canter, D. (1985). Facet theory: Approaches to social research. New York: SpringerVerlag.

Chinese Culture Connection. (1987). Chinese values and the search for culture-free dimensions of culture. Journal of Cross-Cultural Psychology, 18, 143-164.

Cochrane, R., Billig, M. \& Hogg, M. (1979). British politics and the twovalue model. Em M. Rokeach (Org.), Understanding human values: Individual and societal (pp. 179-191). New York: Free Press.

Cronbach, L. (1951). Coefficient alpha and the internal structure of tests. Psychometrika, 16, 297-334.

D’Adamo, O. J. \& Beaudoux, V. G. (1995). Actitudes hacia la democracia: Del modelo clásico liberal a las nuevas democracias participativas. Em O. D’Adamo, V. G. Beaudoux \& M. Montero (Orgs.), Psicología de la acción politica (pp. 81-90) Buenos Aires: Paidós.

Dallari, D. A. (1989). Elementos de teoria geral do Estado. São Paulo: Saraiva.

Davison, M. (1983). Multidimensional scaling. New York: Wiley.

Dawson, P. A. (1979). The formation and structure of political belief systems. Political Behaviour, 1, 99-122.

De Riz, L. (1994). Os desafios da democracia argentina. Em M. Baquero (Org.), Cultura politica e democracia: Os desafios das sociedades contemporâneas (pp. 55-75). Porto Alegre: UFRGS.

Deschamps, J. C. (1989). La double référence de la psychologie sociale. Revue Suisse de Psychologie, 48, 3-13.

Deschamps, J. C. \& Devos, T. (1993). Valeurs, cultures et changement. Intercultures, 1, 17-28.

Doise, W. (1976). L'articulation psychosociologique et les relations entre groupes. Bruxelles: De Boeck.

Doise, W. (1982). L'explicacation en psychologie sociale. Paris: PUF.

Easton, D. (1965). A system analysis of political life. New York: Wiley.

Feather, N. T. (1979). Values correlates of conservatism. Journal of Personality and Social Psychology, 37, 1617-1630.

Feather, N. T. (1984). Protestant ethic, conservatism and values. Journal of Personality and Social Psychology, 46, 1132-1141.

Feather, N. T. (1985). Attitudes, values and attributions: Explanations of unemployment. Journal of Personality and Social Psychology, 48, 876-889.

Feather, N. T. (1989). Attitudes towards high achiever: The fall of the tall poppy. Australian Journal of Psychology, 41, 239-267.

Feather, N. T. (1990). Bridging the gap between values and actions: Recent applications of the expectancy-value model. Em E. T. Higgins \& R. M. Sorrentino (Orgs.), The handbook of motivation and cognition: Foundations of social behavior (Vol. 2, pp. 151-192). New York: Guilford.

Feather, N. T. (1993). Authoritarianism and attitudes: Toward high achievers. Journal of Personality and Social Psychology, 65, 152-164.

Flanagan, S. C (1987). Value change in industrial societies. American Political Science Review, 81, 1303-1319.

Giner, S. (1986). La estrutura lógica de la democracia. Sistema, 70, 3-25.

Gouveia, R., França, D., Da Costa, J. \& Camino, L. (1997). O papel das crenças políticas no comportamento dos eleitores de João Pessoa em 1992 e 1994. Em L. Camino, L. Lhullier \& S. Sandoval (Orgs.), Estudos sobre comportamento politico: Teoria e pesquisa (pp. 107-125). Florianópolis: Letras Contemporâneas.

Guttman, L. (1968). A general nonmetric technique for finding the smallest coordinate space for a configuration of points. Psychometrika, 33 , 469-506.

Helkama, K., Uutela, A. \& Schwartz, S. (1992). Value systems and political cognition. Em G. M. Breakwell (Org.), Social psychology of political and economic cognition (pp. 7-31). London: Surrey University.

Heller, A. (1991). The concept of political revisited. Em D. Held (Org.), Political theory today (pp. 330-343). California: Stanford University.

Hofstede, G. (1980). Culture's consequences. Beverly Hills: Sage. 
Homer, P. M. \& Kahle, L. (1988). A structural equation test of the valueattitude-behavior hierarchy. Journal of Personality and Social Psychology, 54, 638-646.

Inglehart, R. (1971). The silent revolution in Europe: Intergenerational change in post-industrial societies. American Political Sciences Review, 65, 991-1017.

Inglehart, R. (1977). The silent revolution. Princeton: Princeton University.

Inglehart, R. (1991). El cambio cultural en las sociedades industriales avanzadas. Madrid: Siglo XXI.

Inglehart, R. (1994). Modernización y post-modernización: La cambiante relación entre el desarrollo econômico, cambio cultural y político. Em J. D. Nícolas \& R. Inglehart (Orgs.), Tendencias mundiales de cambio en los valores sociales y politicos (pp. 157-170). Madrid: Fundesco.

Iñíquez, L. \& Vázquez, F. (1995). Legitimidad del sistema democrático: Análisis de un discurso autorreferencial. Em O. D’Adamo, V. G. Beaudoux \& M. Montero (Orgs.), Psicología de la acción politica (pp. 3564) Buenos Aires: Paidós.

Kinder, D. R. \& Sears D. O. (1985). Public opinion and political action. Em G. Lindzey \& E. Aronso (Orgs.), The handbook of social psychology (pp. 659-742). New York: Random House.

Kluckhohn, C. (1968). Los valores y las orientaciones de valor en la teoría de la acción. Em T. Parsons \& E. A. Shils (Org.), Hacia una teoría general de la acción (pp. 435-485). Buenos Aires: Editorial Kapelusz.

Kruskal, J. B. \& Wish, M. (1978). Multidimensional scaling. London: Sage.

Lechner, N. (1994). Os novos perfis da política: Um esboço. Em M. Baquero (Org.), Cultura política e democracia: Os desafios das sociedades contemporâneas (pp. 11-24). Porto Alegre: UFRGS.

Levi, L. (1993). Regime politico. Em N. Bobbio, N. Matteucci \& G. Pasquino (Orgs.), Dicionário de política (Vol. 2, pp. 1081-1084). Brasília: UNB.

Lewin, K. (1951/1978). La teoría del campo en la ciencia social. Buenos Aires: Paidós.

Lhullier, L. (1992). Psicologia do autoritarismo: Uma abordagem preliminar. Psico, 24, 141-157.

Lhullier, L. (1996). Socialização política na universidade: Participação, autoritarismo e democracia. Em L. Camino \& P. R. Menandro (Orgs.), A sociedade na perspectiva da psicologia: Questões teóricas e metodológicas (pp. 3746). Rio de Janeiro: ANPEPP.

Lhullier, L. (1997). Autoritarismo, democracia e consciência moral: Uma perspectiva psico-política. Em L. Camino, L. Lhullier \& S. Sandoval (Orgs.), Estudos sobre comportamento politico: Teoria e pesquisa (pp. 25-58). Florianópolis: Letras Contemporâneas.

Likert, R. (1970). A technique for the measurement of attitudes. Em G. F. Summers (Org.), Attitude measurement (pp. 149-158). London: Kershaw.

Lima, M. E. (1997). Valores, participação politica, atitudes face a democracia e ao autoritarismo: Uma análise da socialização politica dos universitários da Paraíba. Dissertação de Mestrado não-publicada, Universidade Federal da Paraíba. João Pessoa, PB.

Lima, M. E. \& Camino, L. (1995). A Política na vida de estudantes universitários: Uma análise em termos de espaço político e de valores. Em M. J. L. Silva (Org.), Iniciados (pp. 11-35). João Pessoa: Editora Universitária.

Lipset, S. M. (1967). O homem politico. Rio de Janeiro: Zahar.

Macpherson, C. B. (1978). A democracia liberal: Origens e evolução. Rio de Janeiro: Zahar.

Maio, G. R. \& Olson, J. M. (1998). Values as truisms: Evidence and implications. Journal of Personality and Social Psychology, 74, 294-311.

Maslow, A. K. (1954). Motivation and personality. New York: Harper e Row.

Menezes, I. \& Campos, B. (1997). The process of value-meaning construction: A cross-sectional study. European Journal of Social Psychology, 27, 55-77.

Middendorp, P. (1978). Progressiveness and conservatism: The fundamental dimension of ideological controversy and their relationship to social class. Haia: Mouton.

Offe, C. (1985). New social movements: Challenging the boundaries of institutional politics. Social Research, 52, 817-868.

Parsons, T. (1957). The social system. New York: Free Press.
Parsons, T., Shils, E. A. \& Olds, J. (1968). Los valores, los motivos y los sistemas de acción. Em T. Parsons \& E. A. Shils (Orgs.), Hacia una Teoría General de la Acción (pp. 67-311). Buenos Aires: Editorial Kapelusz.

Pereira, C. R. \& Camino, L. (1999). Proposta de um modelo psicossociológico para o estudo das atitudes políticas de estudantes universitários: Uma análise em termos de valores materialistas e pós-materialistas. Em M. F. V. Souza (Org.), Iniciados (pp. 427-440). João Pessoa: Editora Universitária.

Pereira, C. R., Lima, M. E. \& Camino, L (1997). A prática política: Uma análise psicossociológica em termos de valores e inserção social. Em M. J. L. Silva (Org.), Iniciados (pp. 199-235). João Pessoa: Editora Universitária.

Rokeach, M. (1968). Beliefs, attitudes and values: A theory of organization and change. San Francisco: Jossey-Bass.

Rokeach, M. (1973). The nature of buman values. New York: Free Press.

Rokeach, M. (1979a). The two-value model of political ideology and British politics. Em M. Rokeach (Org.), Understanding buman values: Individual and societal (pp. 192-196). New York: Free Press.

Rokeach, M. (1979b) Introduction. Em M. Rokeach (Org.), Understanding buman values: Individual and societal (pp. 1-11). New York: Free Press.

Rosanvallon, P. (1996). A história da palavra democracia na época moderna. Perspectivas, 19, 113-129.

Rouquié, A. (1985). O Mistério democrático: Das condições da democracia às democracias sem condições. Em A. Rouquié, B. Lamounier \& J. Schvarzer (Orgs.), Como renascem as democracias (pp. 19-45). São Paulo: Brasiliense.

Sagiv, L. \& Schwartz, S. H. (1995). Value priorities and readiness for outgroup social contact. Journal of Personality and Social Psychology, 69, 437448.

Schmitter, P. (1997). Perspectivas da democracia no mundo contemporâneo: Mais liberal, pré-liberal ou pós-liberal? Em S. Gerschman \& M. L. W. Viana (Orgs.), A Miragem da pós-modernidade: Democracia e politicas sociais no contexto da globalizacão (pp. 31-42). Rio de Janeiro: Fiocruz.

Schwartz, S. H. (1992). Universals in the content and structure of values: Theoretical advanced and empirical testes in 20 countries. Em M. Zanna (Org.), Advances in experimental social psychology (Vol. 25, pp. 1-65). Orlando: Academic Press.

Schwartz, S. H. (1994). Are there universal aspects in the structure and contents of human values? Journal of Social Issues, 50, 19-45.

Schwartz, S. H. (1996). Value priorities and behavior: Applying a theory of integrated value systems. Em C. Seligman, J. M. Olson \& M. P. Zanna (Orgs.), The psychology of values: The Ontario Symposium (Vol. 8, pp. 1-24). Mahwah, NJ: LEA.

Schwartz, S. H. \& Bilsky, W. (1987). Toward a universal psychological structure of human values. Journal of Personality and Social Psychology, $53,550-562$.

Schwartz, S. H. \& Bilsky, W. (1990). Toward a theory of the universal content structure of values: Extensions and cross-cultural replications. Journal of Personality and Social Psychology. 58, 878-891.

Seligman, C.\& Katz, A. (1996). The dynamics of value systems. Em C. Seligman, J. M. Olson \& M. P. Zanna (Orgs.), The psychology of values: The Ontario Symposium (Vol. 8, pp. 53-75). Mahwah, NJ: LEA.

Seliktar, O. (1991). Identifying a society's belief system. Em M. G. Hermann (Org.), Political psychology contemporary problems and issues (pp. 320-354). San Francisco: Jossey-Bass.

Tajfel, H. (1981). Human groups and social categories. New York: Cambridge University.

Tamayo, A. \& Shwartz, S. H. (1993). Estrutura motivacional dos valores humanos. Psicologia: Teoria e Pesquisa, 9, 328-346.

Tamayo, A., Pimenta, M., Rolim, M., Rodovalho, O. \& Castro, P. (1996). Prioridades axiológicas e orientação política. Psicologia: Teoria e Pesquisa, 12, 253-259.

Torres, A. R. R. (1992). Uma análise psicossocial da identificação partidária: O caso dos estudantes da UFPb nas eleições de 1988, 1989 e 1990. Dissertação de Mestrado não-publicada, Curso de Pós-Graduação em Psicologia Social, Universidade Federal da Paraíba. João Pessoa, PB. 
Touraine, A. (1996). O que é a democracia? Petrópolis: Vozes.

Vala, J. (1993). Valores sócio-políticos. Em L. de França (Org.), Portugal, valores europeus e identidade cultural (pp. 221-259). Lisboa: Instituto de Estudos para o Desenvolvimento.

Vala, J. (1994). La emergencia de los valores post-materialistas en Portugal. Em J. D. Nícolas \& R. Inglehart (Orgs.), Tendencias mundiales de cambio en los valores sociales y políticos (pp. 157-170). Madrid: Fundesco.

Ward, J. H. (1963). Hierarchical grouping to optimize an objective function. Journal of American Association, 58, 236-244.
Weber, M. (1904-5/1994). A ética protestante e o espirito do capitalismo. São Paulo: Pioneira.

Williams, R. M. (1979). Change and stability in values and value systems: A sociological perspective. Em M. Rokeach (Org.), Understanding buman values: Individual and societal (pp. 15-46). New York: Free Press.

Recebido em 6/09/2000

Revisado em $8 / 09 / 2000$

Aceito em 8/09/2000

Sobre os autores:

Cícero Pereira é Psicólogo, Mestre em Psicologia Social pela Universidade Federal da Paraíba (UFPB). Professor do Departamento de Psicologia da UCG. Desenvolve pesquisas sobre Valores, Comportamento Político e Direitos Humanos.

Marcus Eugênio Lima é Mestre em Psicologia Social pela Universidade Federal da Paraíba, Doutorando em Psicologia Social pelo Instituto Superior de Ciências do Trabalho e da Empresa e investigador visitante no Instituto de Ciências Sociais da Universidade de Lisboa.

Leoncio Camino é Doutor em Psicologia pela Universidade Católica de Louvain (Bélgica), professor do Departamento de Psicologia da Universidade Federal da Paraíba e Coordenador do Grupo de Pesquisa em Comportamento Político da UFPB. É membro da Comissão de Direitos Humanos do CFP e desenvolve pesquisas sobre Direitos Humanos, Processos de Exclusão Social e Comportamento Político. 